\section{Case Reports in Ophthalmology}

Case Rep Ophthalmol 2018;9:149-153

DOI: $10.1159 / 000486925$

Published online: February 14, 2018
(C) 2018 The Author(s)

Published by S. Karger AG, Basel www.karger.com/cop

This article is licensed under the Creative Commons Attribution-NonCommercial$\begin{array}{lllll}\text { NoDerivatives } & 4.0 & \text { International License } & \text { (CC } & \text { BY-NC-ND) }\end{array}$ (http://www.karger.com/Services/OpenAccessLicense). Usage and distribution for commercial purposes as well as any distribution of modified material requires written permission.

\title{
Rapid Capsular Contraction with Secondary Intraocular Lens Dislocation Associated with Unspecified Rod-Cone Dystrophy: A Case Report
}

\author{
Jocelyn Lam ${ }^{a} \quad$ Bradley Sifrig ${ }^{b}$ Hoon Jung ${ }^{a, c}$ \\ ${ }^{a}$ Department of Ophthalmology, University of Washington, Seattle, WA, USA; ${ }^{b}$ College of \\ Medicine, University of Florida, Gainesville, FL, USA; ${ }^{C}$ Veterans Affairs Puget Sound Health \\ Care System, Seattle, WA, USA
}

\section{Keywords}

Anterior capsular phimosis - Cataract surgery · Intraocular lens dislocation · Rod-cone dystrophy

\begin{abstract}
Purpose: We report an unusual case of rapid and severe anterior capsular contraction associated with secondary intraocular lens (IOL) dislocation following cataract surgery in a patient with unspecified rod-cone dystrophy. Case Report: A 68-year-old woman with a history of uncharacterized bilateral rod-cone dystrophy presented with blurry vision 1 month after cataract surgery. Best corrected visual acuity was 20/40 in the operative eye. Slit-lamp exam showed severe anterior capsular phimosis limiting view of the fundus. Our patient underwent 2 sessions of $\mathrm{Nd}$ :YAG anterior capsulotomy with limited success. Limited anterior vitrectomy was then performed without success due to densely adherent capsular tissue to the anterior surface of the IOL and additional secondary IOL dislocation. She ultimately underwent pars plana vitrectomy, removal of the capsular bag, and IOL exchange with a scleral fixated IOL. Conclusion: Rapid and severe anterior capsular contraction following cataract surgery is rare but appears to be associated with rod-cone dystrophy.

(C) 2018 The Author(s)

Published by S. Karger AG, Basel
\end{abstract}




\section{Case Reports in Ophthalmology}

Case Rep Ophthalmol 2018;9:149-153 DOI: $10.1159 / 000486925$

(C) 2018 The Author(s). Published by S. Karger AG, Basel www.karger.com/cop

Lam et al: Rapid Capsular Contraction with Secondary Intraocular Lens Dislocation Associated with Unspecified Rod-Cone Dystrophy: A Case Report

\section{Introduction}

Anterior capsular contraction syndrome is a well-documented complication following cataract surgery in which there is centripetal constriction and fibrosis of the anterior capsule. This phimosis and fibrosis of the anterior capsule typically occurs over the course of months to years following phacoemulsification surgery. However, rare instances of rapid anterior capsule constriction have been documented in case reports of patients with advanced retinitis pigmentosa $[1,2]$.

We report and discuss the rare case of an elderly woman who experienced rapid anterior capsule phimosis and aggressive fibrosis within 1 month following cataract surgery in the context of uncharacterized rod-cone dystrophy.

\section{Case Report}

A 68-year old woman with a visually significant cataract in the right eye was referred for cataract surgery. The patient had an ocular history significant for myopia, Fuchs' corneal dystrophy, Sjögren syndrome with aqueous tear deficiency, prior hydroxychloroquine use without maculopathy, and uncharacterized clinical rod-cone dystrophy. She had no prior history of ocular surgery. Family and social history were noncontributory. Best corrected visual acuity was 20/40 in the right eye and 20/20 in the left eye with manifest refraction of -3.50 sphere and $-4.25+1.25 \times 090$, respectively. Intraocular pressure by applanation tonometry was 15 and $14 \mathrm{~mm} \mathrm{Hg}$ in the right and left eye, respectively. Slit-lamp exam of both eyes showed 2+ guttae, 3+ nuclear sclerosis, and 1+ central posterior subcapsular cataract with vacuoles. Fundus exam was remarkable for mild temporal optic nerve pallor, peripapillary atrophy, blunted foveal light reflex, prominent choroidal vasculature, and scattered fine pigmentary changes with few bony spicules and inferior paving stones bilaterally. She was clinically described to have an autosomal recessive variant of rod-cone dystrophy.

The patient underwent uncomplicated phacoemulsification with insertion of a singlepiece acrylic intraocular lens (IOL) in the right eye. On postoperative day 1, vision was 20/40 and intraocular pressure $20 \mathrm{~mm} \mathrm{Hg}$ with a centered IOL and clear posterior capsule. At postoperative week 1 , vision for the operative eye was 20/40 with pinhole acuity 20/25 and early $1+$ posterior capsular opacification. At postoperative month 1 , the patient subjectively reported cloudy vision with a best corrected visual acuity of 20/40 with a manifest refraction of $+0.75+0.75 \times 173$. Exam showed a posterior chamber IOL with severe anterior capsular phimosis limiting view of the fundus (Fig. 1). The patient returned 2 weeks later for Nd:YAG anterior capsulotomy with visual acuity declining to 20/250. Nd:YAG anterior capsulotomy was performed creating a partial opening inferonasally due to the variable response of the thick capsule. The patient returned after 2 weeks and was found to have visual acuity of 20/200 with persistent capsular phimosis. Repeat Nd:YAG anterior capsulotomy was attempted with limited response due to the thickness of the opacification. At this point, the patient was consented for limited anterior vitrectomy. During bimanual anterior vitrectomy, the capsular phimosis was found to be extremely adherent to the anterior surface of the lens implant, and multiple unsuccessful efforts were made to remove the phimosis with the vitrector and sharp instruments. Surgery was halted due to IOL instability. The patient was referred to the retina service for surgical consultation and subsequently underwent uncomplicated pars plana vitrectomy, removal of the IOL with its capsular bag, and scleralsutured sulcus-positioned IOL. 


\section{Case Reports in Ophthalmology}

\section{Discussion}

Continuous curvilinear capsulorhexis openings created during cataract surgery are known to contract slightly during the postoperative period in nonpathologic eyes [3]. Anterior capsular contraction syndrome is characterized by excessive contraction and fibrosis of the anterior capsulotomy that can lead to obstruction of the visual axis and secondary complications including pseudophacodonesis, IOL decentration or dislocation, and refractive shifts.

Patients with anterior capsular contraction syndrome are often asymptomatic until they have advanced stage disease with obscuration of the visual axis by the anterior capsule. Patients commonly experience an initial improvement in visual acuity in the first few weeks following their cataract surgery. Over the course of months, progressive loss of vision occurs as the anterior capsule contracts into the visual axis resulting in IOL decentration and symptoms of glare, haloes, or monocular diplopia. Sudden and severe vision loss may indicate IOL dislocation.

The etiology of capsular contraction syndrome is not completely understood, but is believed to result from metaplastic lens epithelial cells causing capsular contraction [4]. Residual anterior lens epithelial cells that remain following cataract surgery undergo a myofibroblastic transformation. These metaplastic lens epithelial cells contain smooth-muscle actin and mediate contraction of the anterior capsule [5].

Several comorbidities (ophthalmic and systemic) have been observed to increase the risk of capsule contraction. Associations with high myopia, small-diameter capsulorhexis, zonular weakness, uveitis, pseudoexfoliation syndrome, and retinitis pigmentosa have been described. Advanced age, diabetes mellitus, and other rarer systemic diseases (Behcet's syndrome and myotonic muscular dystrophy) are also observed to have a higher risk of capsular contraction. In those cases described in the literature, retinitis pigmentosa seems to particularly increase the risk for a more rapid onset of capsular phimosis and fibrosis [1, 2]. In addition, the type of IOL that is implanted appears to influence the development of anterior capsular contraction syndrome. Silicone, acrylic, plate haptic, and polyHEMA IOLs may have more pronounced capsule contraction when compared to older-style rigid PMMA IOLs [6, 7].

Preventative measures can be utilized both during and after cataract surgery to decrease the risk of capsular contraction syndrome in patients with multiple risk factors. Intraoperative measures include the creation of a larger capsulorhexis [3], the use of a capsular tension ring [8], and lens epithelial cell clean-up at the time of phacoemulsification [9]. In the early postoperative period for high-risk patients, radial relaxing incisions in the anterior capsule can be created by Nd:YAG to further decrease the risk of anterior capsular contraction syndrome [10]. The mechanism explaining the protective effects of these radial relaxing incisions is believed to be a biomechanical stress release of centripetal forces acting on the anterior capsule [11].

The management of anterior chamber contraction syndrome involves a variety of techniques to remove the anterior capsule from the visual axis. Nd:YAG laser anterior capsulotomy is the most frequent method of treatment and provides a relatively quick and painless solution for the patient [12]. However, potential drawbacks of this approach have been reported and include delayed dislocation of the IOL [13] and an increased risk for inflammation and recurrence due to cellular debris [14].

In cases of anterior capsular contraction syndrome such as in our case, where there is thick fibrosis of the capsule, surgical intervention may be required to clear the visual access. Various surgical approaches have been reported. The more traditional method involves sur- 
gical peeling in cases of thick and fibrotic anterior capsule [15]. Using long, straight, and pointed scissors to cut the fibrotic membrane from the visual access has also been proposed [14].

\section{Conclusion}

Although rapid anterior capsular contraction following cataract surgery with IOL placement has been described in eyes with advanced retinitis pigmentosa, we describe the case of a patient with uncharacterized rod-cone dystrophy. In our case, the capsular phimosis was both rapid and severe, which led to a complicated postoperative course involving secondary IOL dislocation and ultimately required IOL exchange with a scleral fixated IOL. Continued awareness and further mechanistic studies are needed to characterize this association between rapid anterior capsular contraction and retinal dystrophies.

\section{Acknowledgements}

The work to present this case report is supported by an unrestricted grant from the Research to Prevent Blindness (RPB).

\section{Statement of Ethics}

Patient consent was obtained along with IRB approval for the publication of this case report. No personally identifiable information was utilized.

\section{Disclosure Statement}

The authors have no conflicts of interest or proprietary interest in any of the topics or products presented in this paper.

\section{References}

1 Jin-Poi T, Shatriah I, Khairy-Shamel ST, Zunaina E: Rapid anterior capsular contraction after phacoemulsification surgery in a patient with retinitis pigmentosa. Clin Ophthalmol 2013;7:839-842.

-2 Nikpoor N, Stone DU: Rapid capsular phimosis in retinitis pigmentosa. Ophthalmic Surg Lasers Imaging 2010, DOI: 10.3928/15428877-20100726-12.

-3 Joo CK, Shin JA, Kim JH: Capsular opening contraction after continuous curvilinear capsulorhexis and intraocular lens implantation. J. Cataract Refract Surg 1996;22:585-590.

-4 Marcantonio JM, Rakic JM, Vrensen GF, Duncan G: Lens cell populations studied in human donor capsular bags with implanted intraocular lenses. Invest Ophthalmol Vis Sci 2000;41:1130-1141. Davison JA: Capsule contraction syndrome. J Cataract Refract Surg 1993;19:582-589.

Cochener B, Jacq PL, Colin J: Capsule contraction after continuous curvilinear capsulorhexis: poly(methyl methacrylate) versus silicone intraocular lenses. J Cataract Refract Surg 1999;25:13621369.

7 Gonvers M, Sickenberg M, van Melle G: Change in capsulorhexis size after implantation of three types of intraocular lenses. J Cataract Refract Surg 1997;23:231-238.

-8 Gimbel HV, Sun R: Role of capsular tension rings in preventing capsule contraction. J Cataract Refract Surg 2000;26:791-792. 
$\$ 9$ Tadros A, Bhatt UK, Abdul Karim MN, Zaheer A, Thomas PW: Removal of lens epithelial cells and the effect on capsulorhexis size. J Cataract Refract Surg 2005;31:1569-1574.

$\checkmark 10$ Hayashi K, Yoshida M, Hirata A, Hayashi H: Anterior capsule relaxing incisions with neodymium:YAG laser for patients at high-risk for anterior capsule contraction. J Cataract Refract Surg 2011;37:97-103.

11 Wang YL, Wang ZZ, Zhao L, Xiong SH, Li Q, Wang NL, Sun AQ: Finite element analysis of neodymium: yttrium-aluminum-garnet incisions for the prevention of anterior capsule contraction syndrome. Chin Med J 2013;126:692-696.

12 Chawla JS, Shaikh MH: Neodymium:YAG laser parabolic anterior capsulotomy in extreme capsule contraction syndrome. J Cataract Refract Surg 1999;25:1415-1417.

-13 Tuft SJ, Talks SJ: Delayed dislocation of foldable plate-haptic silicone lenses after Nd:YAG laser anterior capsulotomy. Am J Ophthalmol 1998;126:586-588.

14 Panagopoulos A, Chalioulias K, Kirkby GR: A new approach in the surgical management of anterior capsular phimosis syndrome. Ophthalmic Res 2009;42:221-223.

15 Reyntjens B, Tassignon M-J, Marck EV: Capsular peeling in anterior capsule contraction syndrome: surgical approach and histopathological aspects. J Cataract Refract Surg 2004;30:908-912.
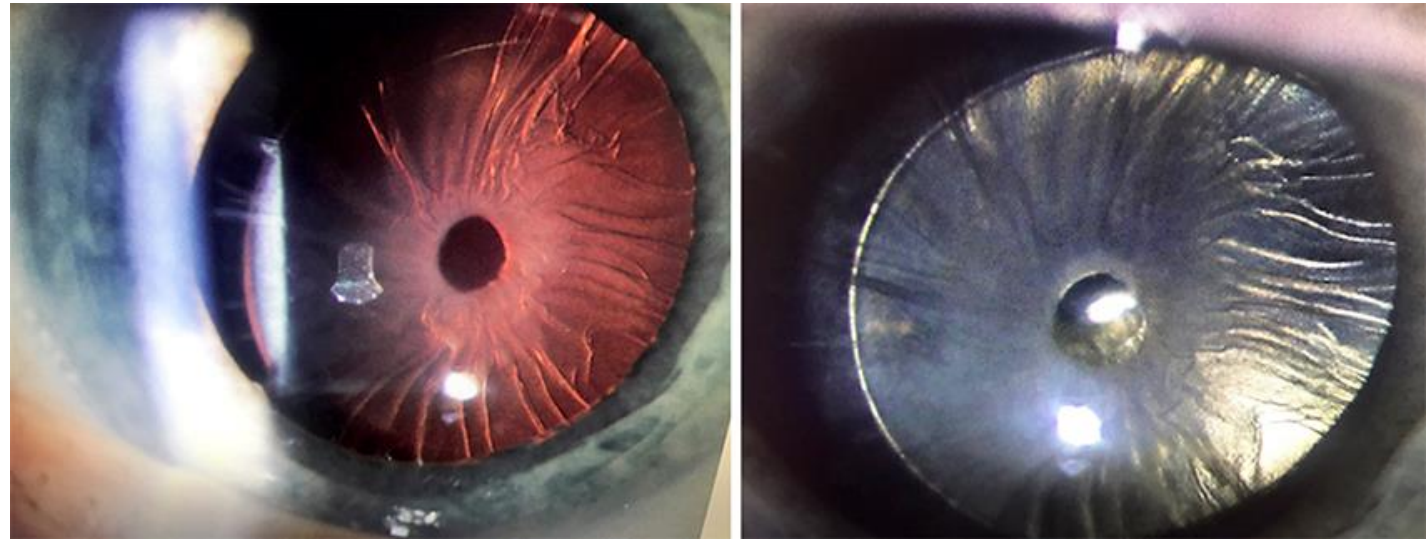

Fig. 1. Slit-lamp photos at 1 month after the operation showing severe anterior capsular phimosis and visible zonules. 